\begin{tabular}{|l|l|l|l|l|l|}
\hline MUNIBE Antropologia-Arkeologia & $n^{\circ} 68$ & $85-100$ & DONOSTIA & 2017 & ISSN 1132-2217 • eISSN 2172-4555 \\
\hline
\end{tabular}

\title{
Regreso a la cueva de El Morrón (Torres, Jaén): revisión arqueológica treinta y cinco años después de su descubrimiento
}

\author{
Return at El Morrón cave (Torres, Jaén): \\ archaeological review thirty-five years after its discovery
}

\begin{abstract}
PALABRAS CLAVES: Sur Península Ibérica, cueva decorada, Paleolítico superior, contexto arqueológico interno, Altomedieval. GAKO-HITZAK: Iberiar penintsularen hegoaldea, apaindutako haitzuloa, Goi Paleolitoa, barneko testuinguru arkeologikoa, Goi Erdi Arokoa. KEY WORDS: South Iberian Peninsula, decorated cave, Upper Paleolithic, inner archaeological context, early medieval.
\end{abstract}

\section{José L. SANCHIDRIÁN TORTI(1), Ma Ángeles MEDINA-ALCAIDE(2), Cristina LIÑÁN BAENA(3), Yolanda del ROSAL PADIAL(4), José $M^{a}{ }^{2}$ COBOS PASTOR(5), Rosa Mª RUIZ-MÁRQUEZ ${ }^{(6)}$ y Antonio TORRES RIESGO(7)}

\section{RESUMEN}

En este artículo presentamos el estudio arqueológico desarrollado en el marco de la Actividad Arqueológica Puntual de "Diagnóstico destinado a la preservación y propuesta de medidas correctoras para la conservación de la cueva de El Morrón (Torres, Jaén)" (2014-2015). La metodología aplicada ha consistido en la revisión sistemática de la totalidad de las superficies endokársticas, tanto parietales como pavimentarias, la documentación arqueométrica y catalogación de los restos arqueológico, tanto conocidos como inéditos, haciendo especial hincapié en su estado de conservación; la documentación fotográfica, la restitución gráfica mediante el tratamiento digital de las evidencias rupestres (calcos) junto con el análisis cronológico de todas evidencias de frecuentación desde una perspectiva estilística (motivos figurativos parietales) como radiométrica (datación de un resto óseo). En el piso de la cueva hemos detectado varios fragmentos de cerámica tanto a mano como a torno, una lasca de sílex y varios restos óseos, algunos humanos, junto con una acumulación antrópica de bloques y tierra. El repertorio gráfico de la cueva, aunque sigue siendo muy escueto, se ha ampliado con la representación parcial de un posible zoomorfo, varias manchas rojas y trazos negros. También presentamos la datación C14-AMS de uno de los restos óseos humanos. Asimismo, hemos constatado un importante deterioro de los figuras paleolíticas conocidas.

\section{LABURPENA}

Artikulu honetan, "El Morrón (Torres, Jaén) leizea kontserbatzeko diagnostikoa eta neurri zuzentzaileen proposamena" (2014-2015) Jarduera Arkeologiko Puntualaren esparruan garatutako azterlan arkeologikoa aurkeztuko dugu. Hona hemen aplikatutako metodologia: gainazal endokarstiko guztiak, bai hormetakoak, bai zolakoak, sistematikoki aztertzea, dokumentazio arkeometrikoa eta hondakin arkeologikoen katalogazioa, bai ezagunak, bai argitaragabeak, haien kontserbazio-egoerari arreta berezia eskainita; argazki-dokumentazioa, leheneratze grafikoa labarretarako ebidentziak modu digitalean tratatuta (kalkoak) eta frekuentatze-ebidentzia guztien analisi kronologikoa ikuspegi estilistikotik (hormetako irudi-motiboak) eta erradiometrikotik (hezur-hondakin baten datazioa). Leizearen zoruan zenbait zeramika-zati detektatu ditugu, bai eskuz, bai tornuz, silexezko harri zabal bat eta hezur-hondakin batzuk, horietako batzuk gizakienak, eta bloke eta lurraren metatze antropiko bat. Leizearen errepertorio grafikoak oso soila izaten jarraitzen duen arren, hedatu egin da zoomorfo izan litekeen baten errepresentazio partzialarekin, zenbait orban gorri eta trazu beltzekin. Giza hezur-hondakin baten C14-AMS datazioa ere aurkeztu dugu. Era berean, irudi paleolitiko ezagunek narriadura nabarmena jasan dutela ikusi dugu.

\section{ABSTRACT}

This paper provides an archaeological review included in the Actividad Arqueológica Puntual of "Diagnóstico destinado a la preservación y propuesta de medidas correctoras para la conservación de la cueva de El Morrón (Torres, Jaén)" (2014-2015). The applied methodology has lied in the systematical review of the whole karst environments, both in walls and floors, archaeometric data and cataloging of the archaeological remains, either both known as unpublished, highlighting its state of preservation and the photographical documentation, the graphic restitution of rock art (tracings) together with the chronological analysis of every of the archaeological remains from the point of view of a stylistic approach of rock art and a radiometric one of an only human bone. On the floor we have found several pieces of handmade and wheelmade pottery, a flint and some human bones remains, joined to an anthropic stack of blocks and sediments. The parietal art, although it continues to be modest, has been increased with the partial representation of a possible zoomorphic figure, several red spots and black marks. We also provide the C14-AMS dating of one of the human bone. Finally, we have seen an important deterioration of the Paleolithic known figures.

\footnotetext{
(1) Área de Prehistoria. Dpto. Geografía y Ciencias del Territorio, Universidad de Córdoba (UCO). Plaza Cardenal Salazar s/n. 14071-Córdoba gt1satoj@uco.es

(2) Dpto. Geografía, Prehistoria y Arqueología, Grupo de Investigación en Prehistoria IT-622-13. Universidad del País Vasco UPV/EHU

(3) Instituto de Investigación Cueva de Nerja. Dpto. de Ecología y Geología, Facultad de Ciencias, Universidad de Málaga.

(4) Instituto de Investigación Cueva de Nerja.

(5) Área de Prehistoria. Dpto. Geografía y Ciencias del Territorio, Universidad de Córdoba (UCO).

(6) Área de Prehistoria. Dpto. Geografía y Ciencias del Territorio, Universidad de Córdoba (UCO).

(7) Área de Prehistoria. Dpto. Geografía y Ciencias del Territorio, Universidad de Córdoba (UCO).
} 


\section{1.- INTRODUCCIÓN}

Este trabajo está enmarcado dentro de la Actividad Arqueológica Puntual titulada "Diagnóstico destinado a la preservación y propuesta de medidas correctoras para la conservación de la cueva de El Morrón (Torres, Jaén)" aprobada por la Consejería de Cultura, Educación y Deporte de la Junta de Andalucía bajo la dirección de una de nosotras (M.M.A) y llevada a cabo entre los años 2014 y 2015.

El objetivo principal de esta intervención fue rescatar a la cueva de El Morrón del olvido científico y administrativo en que se encontraba, mediante la realización de un examen integral e interdisciplinar de su estado actual de preservación, con la finalidad de proponer a las instituciones que gestionan este B.I.C. una serie de medidas correctoras para su conservación adecuada en base a un chequeo global.

La intervención abarcó el trabajo de las tres grandes disciplinas presentes en los medios kársticos antropizados: a) Arqueología: prospección arqueológica superficial de las paredes y los suelos de la gruta, documentando los indicios antrópicos y sus alteraciones, junto con el análisis cronológico de la frecuentación prehistórica e histórica a la cueva; b) Biología: examen de la microbiota del aire y superficies, así como de la fauna presente en el endokarst; c) Geología: reconocimiento geomorfológico preliminar de la gruta, comprobación de las características físico-químicas de las aguas de goteo y registro puntual de los principales parámetros medioambientales del aire, tanto en el exterior como en el interior de la cueva. En concreto, en este artículo presentamos el trabajo desarrollado, la metodología aplicada y los resultados obtenidos en el ámbito arqueológico. Los resultados de las otras disciplinas han sido publica- dos pormenorizadamente con anterioridad (Sanchidrián et al., 2015).

\section{2.- DESCRIPCIÓN DE LA CAVIDAD}

La cueva de El Morrón es, hoy día, la única cavidad con arte paleolítico de la provincia de Jaén (Andalucía, España). Se ubica en el municipio de Torres, en la vertiente Norte del cerro epónimo, el cual forma parte de la Sierra del Aznaitín, dentro del Parque Natural de Sierra Mágina. La cavidad se desarrolla en calizas del Cretácico Superior, pertenecientes a las zonas externas de la Cordillera Bética que forman parte del Prebético de Jaén. Éste comprende varios afloramientos aislados, separados entre sí por accidentes tectónicos, que constituyen relieves elevados, como las sierras de GoIondrina y Bédmar-Jódar y la propia Sierra del Aznaitín (Igme, 1992) (Fig. 1).

La cavidad, a 1000 m.s.n.m., se desarrolla sub-horizontalmente en dirección NE-SW. En la figura 2 presentamos su planimetría general, confeccionada a partir de la topografía de López y Soria (1985) que hemos completado con los elementos geomorfológicos junto con nuevas plantas y secciones. La galería de entrada, de 8 metros de longitud y 1,5 metros de anchura media, y con un desnivel casi nulo o escaso, tiene una morfología tubular y sección transversal lenticular, y parece responder a la de un conducto kárstico originado en condiciones freáticas. Tras evolucionar las condiciones de la cueva de freáticas a vadosas, este Conducto de Acceso fue taponado por la entrada de sedimentos clásticos alogénicos procedentes del exterior, que fueron excavados de forma antrópica. Hoy día, sólo se observan restos de una brecha cementada, adosados a ambas paredes de la galería.
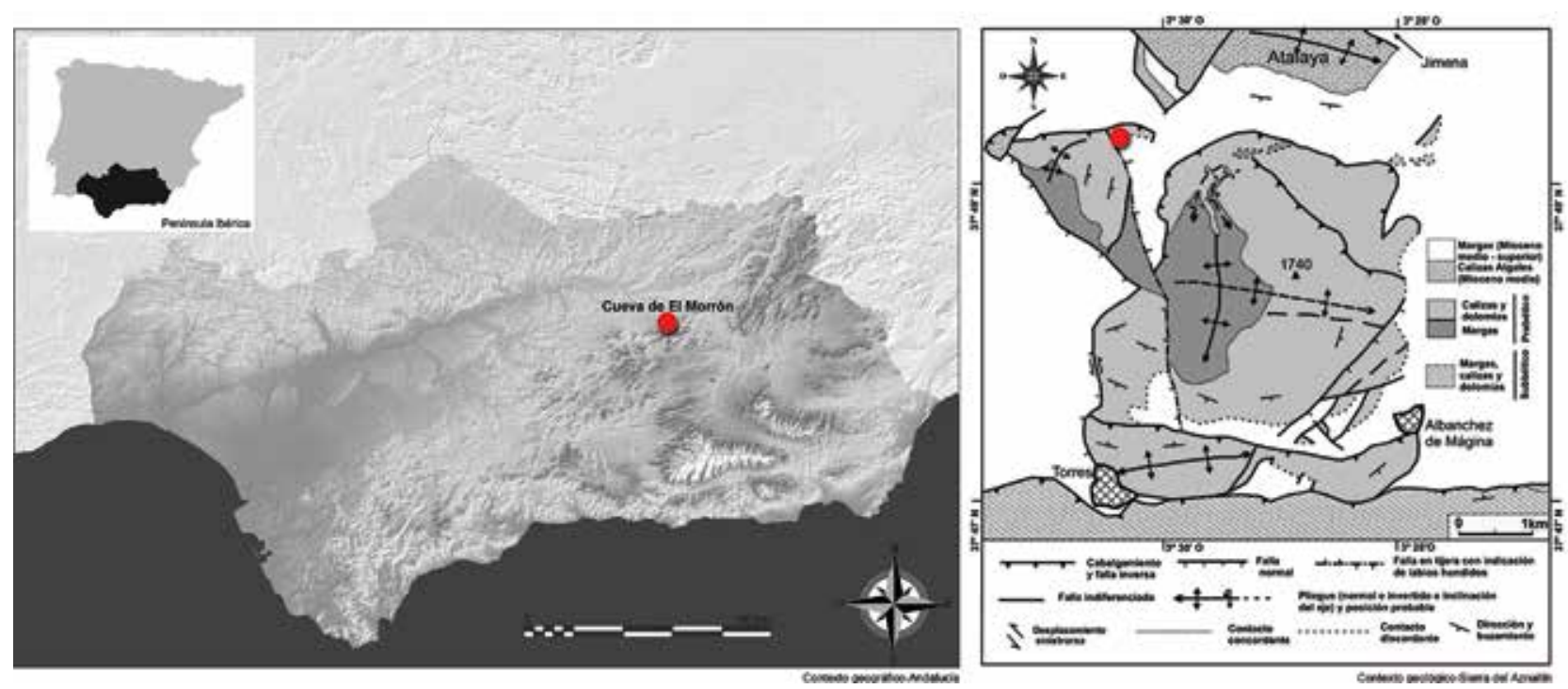

Fig. 1. Localización de la cueva de El Morrón en el contexto geográfico de la Península lbérica, así como geológico de la Sierra del Aznaitín (modificado a partir de Sanz de Galdeano et al., 2013) / Location of El Morrón cave within the geographical context of the Iberian Peninsula and the geological context of the Sierra del Aznaitín (modified from Sanz de Galdeano et al., 2013). 
Tras recorrer la galería de entrada, se alcanza la Sala Principal de la gruta (Fig. 2), que posee una planta subcircular y unas dimensiones de 34 metros de longitud por 25 metros de anchura. En ella existen formas de precipitación química, si bien predominan las de colapso y disolución. El colapso de bloques de la roca encajante y su posterior eliminación por disolución podría ser uno de los factores que ha contribuido de manera notable a la ampliación de este sector. Otro aspecto destacado es la acumulación de material detrítico y de moonmilk en el piso, que estaría relacionado con la posterior erosión y/o alteración antrópica de los bloques y paredes expuestas tras el colapso.

Los bloques colapsados en el centro de esta sala delimitan el acceso al Camarín de las Pinturas (Fig. 2), al sureste de la entrada de la cavidad, donde se ubican los principales motivos de arte rupestre. Este espacio, de 3,80 metros de anchura, 8,90 metros de longitud y 1,66 metros de altura media, muestra un perfil transversal lenticular que, en algunos sectores, parece evolucionar en profundidad hacia perfiles rectangulares.

Completan la cueva los espacios de la Galería Lateral y la Galería Chimenea (Fig. 2). La primera ubicada al este de la entrada, con una extensión de 13 metros de longitud, una anchura media de 1,5 metros y un buzamiento acusado. La segunda tiene 7 metros de desarrollo, una anchura máxima de 5 metros y un desnivel muy pronunciado, siendo totalmente vertical en el primer tramo.

\section{3.- HISTORIA DE LAS INVESTIGACIONES}

La cueva de El Morrón fue descubierta el 19 de abril de 1981 por Juan A. Bonilla, Carmen Ortiz, Ricardo Blanco y Ricardo Ruiz, espeleólogos burgaleses de los grupos "Amaya" y "Equus". A partir de una información recibida de Luis Benavides (Técnico de ICONA en Jaén), quien apuntaba la posible existencia de cavidades con arte rupestre prehistórico en la zona, este grupo se trasladó al lugar en una campaña, titulada Operación "Aznatín-81", para estudiar y explorar el karst. Tras unos primeros trabajos que se centraron, fundamentalmente, en la conocida estación de arte esquemático de la Cueva de Las Grajas (Jimena, Jaén), a 3,5 kilómetros de El Morrón en línea recta, e invitados por el entonces Teniente de Alcalde de Jimena, Juan

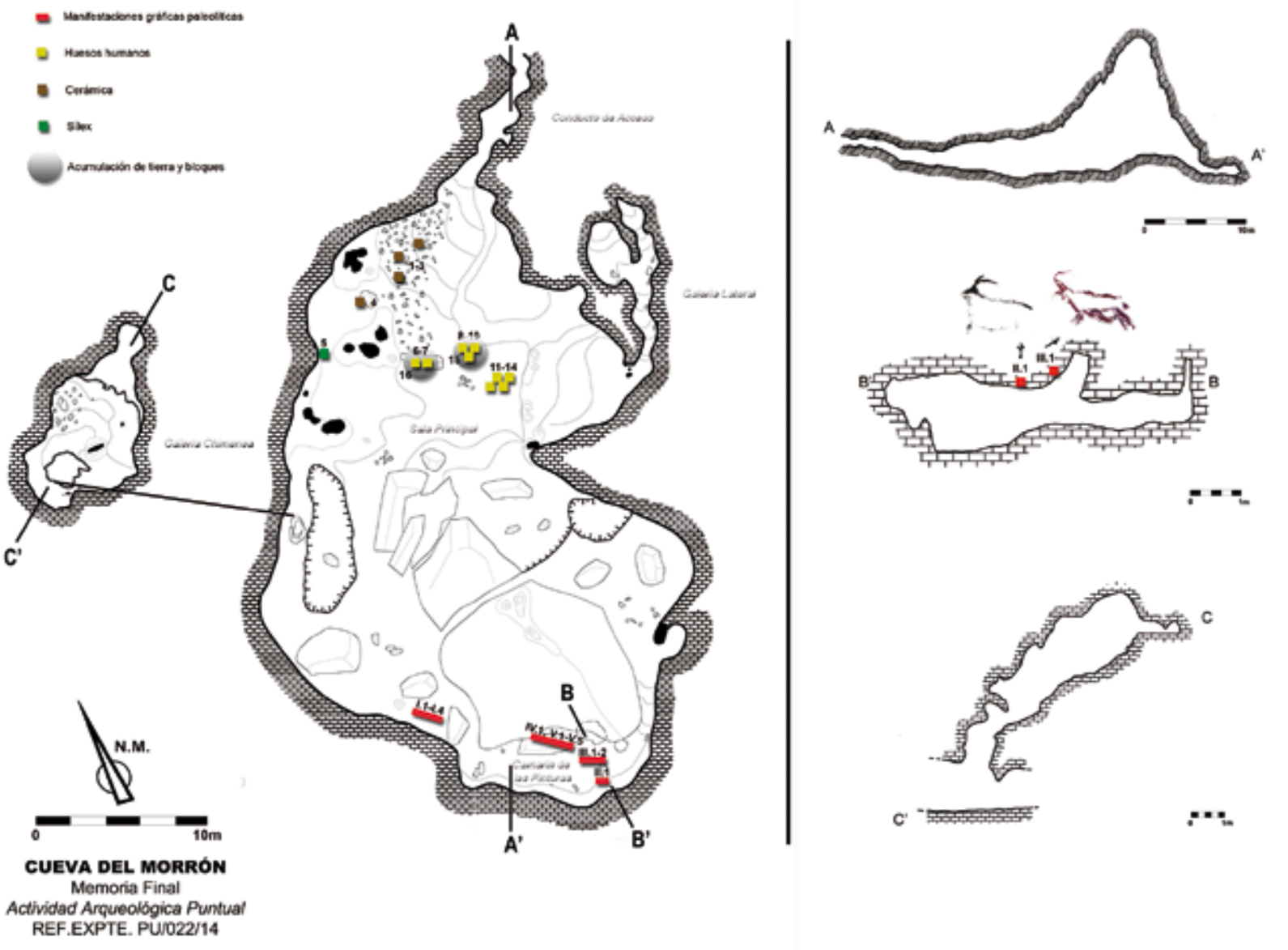

Fig. 2. Planimetría y secciones adjuntas de la cueva de El Morrón con la localización de los restos arqueológicos superficiales del piso y las manifestaciones gráficas paleolíticas / Ground plan and sections for El Morrón cave, showing the location of cave-floor surface archaeological remains and of Paleolithic signs. 
Solas, el colectivo partió a visitar la cueva de El Morrón, donde descubrieron las pinturas rupestres paleolíticas (Bonilla et al., 1982; Sanchidrián, 1982).

Fruto de este descubrimiento se gestan, de forma más o menos simultánea, las tres primeras publicaciones sobre el arte rupestre de la cavidad. En primer lugar, la ya mencionada Operación "Aznatín-81" implicó una publicación en la revista Mesetaria, donde se relata detalladamente el trabajo realizado en la zona por el grupo espeleológico, entre el cual se encuentra el hallazgo de las pinturas rupestres de la cueva de El Morrón. En este trabajo se presentan los primeros "calcos" y fotografías en blanco y negro de los que tenemos constancia, junto con una primera descripción de las figuras (identificadas por el grupo espeleológico como dos cérvidos o cabras y un jabalí) y unas someras notas sobre su adscripción cronocultural, situándolas en fechas anteriores a las esquemáticas, vinculadas con los "estilos levantinos y ojoguareñenses" (Bonilla et al., 1982: 99).

En segundo lugar, aunque insistimos, de forma más o menos simultánea en el tiempo, el entonces Director de la revista Zephyrvs, el Prof. Francisco Jordá, previo conocimiento del descubrimiento, encarga a uno de nosotros (J.L.S.T.) una publicación sobre las grafías de El Morrón para esta revista. El objetivo era "dar a conocer tan importante hallazgo, situado al sur de Sierra Morena, que amplía, en el corazón de Andalucía, el área del arte rupestre paleolítico peninsular" (Sanchidrián, 1982: 5, Nota del Director de la revista). En ese artículo se confirma en base a datos tecno-estilísticos la correspondencia de los dos zoomorfos reconocidos (dos cápridos, uno rojo y otro negro) a tiempos pleistocenos, además de otros vestigios y restos de pintura detectados, y se presentan la planimetría, calcos y las primeras fotografías en color de los motivos figurativos; todo ello, realizado en una única jornada de trabajo en la cavidad.

También en el mismo año se publica una pequeña monografía sobre las pinturas rupestres de la cueva de El Morrón (López et al., 1982). Son estos tres primeros estudios, de desigual calado y categoría científica, los únicos que se basan en el trabajo in situ en la caverna. Conforme avanzamos en el tiempo y hasta la actualidad, el resto de publicaciones que aluden a la cueva de El Morrón se han servido de ellas para la obtención de información sobre la cavidad.

\section{4.- EXAMEN INTEGRAL E INTERDISCIPLINAR DEL ESTADO ACTUAL DE LA CUEVA DE EL MORRÓN}

\subsection{Los restos arqueológicos en superficie}

En primer lugar, se ha realizado la revisión sistemática superficial del piso de la cueva, registrando todos los restos antrópicos y animales con independencia de su cronología. Esta actividad se desarrolló en paralelo con la retirada de basuras y restos orgánicos en descomposición del interior de la gruta, como medida urgente de preservación del sitio.

Para esta observación pormenorizada, dividimos el suelo en 9 transeptos longitudinales de 3 metros de ancho al eje de desarrollo de la cavidad. En cada sector trabajaron dos prospectores/as. La revisión se vio favorecida por equipamiento espeleológico para la progresión y seguridad internas (Cascos Petzl Spelios 14 leds de luz fría y blanca) y la utilización de medios individuales de iluminación (Lámparas flexibles Strip Light KB8 de 3-4 horas de autonomía y 130 leds de luz blanca). En algunos casos se usaron lupas de mano

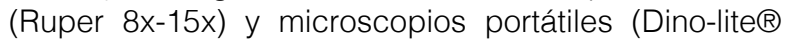
modelos AM7013MZR-R4 10x-70x,200x, AM7012MZT4 400x-460x), conectados a un ordenador portátil (MacBook Air 11") para la observación detallada de los vestigios y su adecuada caracterización.

La recogida de información la realizamos a través de fichas normalizadas, documentando de cada evidencia: la naturaleza, sus dimensiones, si es un elemento aislado o un conjunto, el estado de conservación, su localización en la planimetría y su relación con otros restos. Esta información, posteriormente, fue incluida en una base de datos creada ex professo en el software Filemaker Pro®.

Finalmente procedimos a la documentación fotográfica de cada vestigio, tanto en detalle como general del contexto de procedencia. Las herramientas usadas fueron: a) para fotografía estándar Canon EOS 20D + Canon EF-S 18-55mm; b) para macrofotografías Nikon D610 + AF-S DX Micro-NIKKOR 40mm f/2.8G + LED Macro Ring Flash FC100; y c) para la caracterización dimensional de las imágenes digitales jalones y escalas básicas.

Gracias a la metodología comentada, en la cueva de El Morrón hemos detectado un total de 49 restos o conjuntos de restos a nivel superficial en el piso. Las categorías contemplan las naturalezas siguientes: ósea (44-diferenciando, cuando nos fue posible, entre restos animales y antrópicos-), cerámica (4) y lítica (1 -sílex-). Un porcentaje muy elevado coincide con restos de naturaleza ósea (90\%), seguido a bastante distancia de la cerámica (8\%), a torno y a mano, y de un indicio de industria lítica tallada (2\%).

En cuanto a los vestigios óseos de fauna, la mayoría corresponden a porciones esqueléticas contemporáneas, insertadas en la cavidad por procesos naturales (escorrentías, inclusiones de animales troglófilos y troglóxenos, etc.). La única pieza lítica no evidencia ningún rasgo diagnóstico, al consistir en una pequeña porción de la extremidad proximal de un producto de talla. Por su parte, en el material cerámico pudimos diferenciar entre algunos fragmentos vidriados y a torno de cronología histórica, y otros fragmentos de cerámica a mano, con pastas oscuras y que podrían correspon- 
der a periodos de la Prehistoria reciente o, incluso, a ciertas producciones groseras altomedievales (Solaun, 2006; Gutiérrez, 1986).

En lo concerniente a las porciones óseas humanas, contabilizamos un total de 6 conjuntos de restos que engloban 10 huesos o fragmentos. A continuación, enumeramos los restos de manera provisional, en cuanto que la caracterización osteológica la hemos realizado in situ y sin desplazamiento de los restos, muchos de los cuales se localizan semienterrados: 2 vértebras, 2 falanges, 1 metacarpo, 1 tibia, 2 fracciones de fémur -una distal y otra proximal-, 1 cúbito o metacarpo (semienterrado) y 1 hueso corto indeterminado. Tres de estos restos, en concreto 1 falange, 1 tibia y la porción distal de fémur se localizan en el interior de una acumulación artificial de tierra y bloques de pequeño y mediano tamaño parcialmente destruida (Fig. 3). En el análisis para la obtención de una cronología numérica de los vestigios óseos hemos empleado precisamente ese fragmento de fémur, que ha sido datado por C14AMS en 1.080 +/- 30 BP (Tabla I).

Este resultado podría sugerir el uso como lugar de enterramiento de la cavidad en época altomedieval, si bien los resultados disponibles y el nivel de análisis resultan muy limitados aún como para realizar esta afirmación. Otras cuevas con patrones de inhumaciones en cavidades durante la Tardoantigüedad y la Alta Edad Media han sido registradas en territorios de Cantabria y País Vasco, (Hierro, 2002; Hierro, 2011; Gutiérrez y Hierro, 2012a y 2012b). En el Sur Peninsular sería un ejemplo único, encontrando sólo la reutilización de algunos ambientes subterráneos tipo conjuntos megalíticos (no cuevas naturales) como lugares de inhumación; este sería el caso, del empleo del atrio del Dolmen de Menga (Antequera, Málaga) empleado como lugar de enterramiento y con una de las dataciones coetáneas a la obtenida en El Morrón (Díaz-Zorita y García-Sanjuán, 2012).

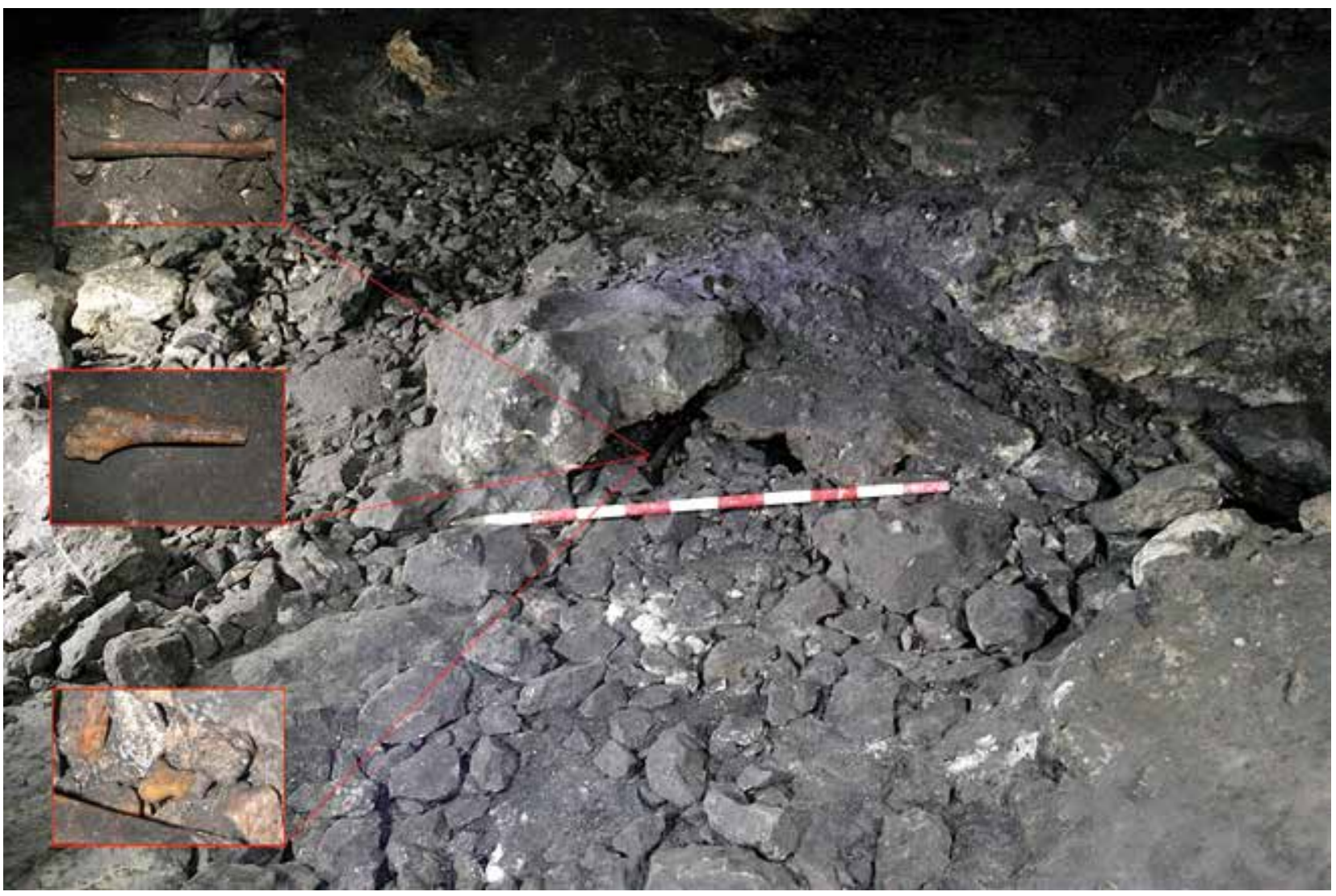

Fig. 3. Acumulación artificial de tierra y bloques de mediano tamaño parcialmente destruida, junto con los huesos humanos localizados en su interior: a) tibia: b) fragmento distal de fémur (espécimen datado); c) falange. / Partially-destroyed artificial mound of earth and medium-sized blocks, together with human bones found within: a) tibia; b) distal fragment of femur (dated specimen); c) phalanx.

\begin{tabular}{|c|c|c|c|c|c|c|}
\hline Muestra & Naturaleza & Ref. lab. & Curva de cal. & Datación convencional & Cal. AD & Cal. BP \\
\hline MOR-1 & $\begin{array}{c}\text { Fragmento de fémur de } \\
\text { Homo sapiens sapiens }\end{array}$ & Beta-428656 & INTCAL13 (Reimer et al. 2013) & $1080 \pm 30$ & $895-1020$ & $1055-930$ \\
\hline
\end{tabular}

Tabla 1: Resultado de la datación de C14-AMS realizada sobre un fragmento de fémur humano localizado en la cueva de El Morrón / Results for C14-AMS dating of a fragment of human femur found at El Morrón cave. 
Además, en la gruta hemos detectados alteraciones antrópicas de los sedimentos endokársticos. Por un lado, se registró otra acumulación intencional de bloques y tierra similar a la que emanan semienterrados los restos humanos citados arriba. Por otro lado, del fondo de la Galería Principal ha sido extraído un volumen considerable de moonmilk, el cual se sacó de la cavidad ante la ausencia de escombrera. En algunos de los "perfiles estratigráficos" de esta extracción existen señales de la herramienta empleada en la excavación, que presenta una forma triangular y cuatro puntas. La datación de esta actividad resulta complicada de determinar, ya que el recurso extraído (presumiblemente el carbonato cálcico para la obtención de cal por calcinación) es un material muy usado desde la antigüedad hasta época contemporánea para fines diversos (mortero/argamasa, enlucido, curtido de pieles, fertilizante, desinfectante, etc.). También parte del pavimento del Conducto de Acceso se encuentra notablemente pulido, fruto del tránsito reiterado de visitantes y, probablemente, por la retirada del material sedimentario comentado.

En la tabla II resumimos los restos antrópicos localizados en superficie en la cueva de El Morrón y en la figura 2 su localización en la planimetría general del yacimiento (ver supra).

\begin{tabular}{|c|c|}
\hline $\mathbf{N}^{\mathbf{0}}$ & Naturaleza \\
\cline { 1 - 1 } 2 & \multirow{2}{*}{ Fragmentos de galbo de cerámica a mano de pasta oscura y lisa } \\
\cline { 1 - 1 } 3 & \\
\hline 4 & Cerámica vidriada \\
\hline 5 & Lasca de sílex \\
\hline 6 & Cúbito o metacarpo \\
\hline 7 & Hueso corto \\
\hline 8 & Tibia \\
\hline 9 & Fragmento de fémur distal \\
\hline 10 & Falange \\
\hline 11 & Fragmento de fémur proximal \\
\hline 12 & Falange \\
\hline 13 & Vértebras \\
\hline 14 & Acumulación de bloques y tierra \\
\hline 15 & \\
\hline 16 & \\
\hline
\end{tabular}

Tabla 2: Restos arqueológicos en superficie en el piso de la Sala Principal de la cueva de El Morrón / Cave-floor surface archaeological remains in the Principal Chamber of the El Morrón cave.

\subsection{Las manifestaciones parietales}

\subsubsection{Descripción}

Tras la prospección superficial del piso, llevamos a cabo la revisión de la totalidad de las paredes y techos. Para ello, dividimos el endokarst en ocho secto- res o sub-sectores geomorfológicos (sectores naturales): Conducto de Acceso, Sala Principal (dadas sus dimensiones fue subdivido en pared Este, Sur y Oeste), Camarín de las Pinturas, Galería Chimenea y Galería Lateral. Dos equipos independientes de dos personas comenzaron con la revisión ocular minuciosa de las superficies parietales, registrando cualquier evidencia de pintura o grabado antrópicos independiente, a priori, de su cronología. Tras finalizar cada sector, ambos equipos contrastaron la información obtenida.

Se emplearon las mismas herramientas y material técnico que para la revisión del suelo, junto con una cámara digital Canon PowerShot SX150 IS con el plugin DStrech@ incorporado. Esta herramienta nos permite visualizar in situ desde el visor de la cámara compacta, de manera instantánea y preliminar, fotografías en falso color de superficies con potencial gráfico. No obstante, esta actividad no sustituye en ningún caso el tratamiento informático posterior en laboratorio, y sólo sirve de apoyo al reconocimiento visual en la cavidad de pigmentos muy desvaídos. También, en algunos casos, se usaron las lupas de mano y los microscopios portátiles, para la observación detallada de los vestigios y su adecuada caracterización. Además de los jalones y las escalas básicos para la representación dimensional de las imágenes digitales, empleamos la escala colorimétrica ColorCheker Passport para la restitución del color real de las fotografías y la medición del color LAB y RGB que preservan en la actualidad los motivos figurativos (Pereira, 2013; Ruiz y Pereira, 2014).

La recogida de información la realizamos a través de fichas normalizadas, documentando de cada evidencia parietal una serie de caracteres intrínsecos (temática, técnica, modo de implantación, medio de ejecución y dimensiones) y extrínsecos (soporte y alteraciones, estado de conservación, localización en el paisaje subterráneo y relación con otros motivos). Esta información, asimismo, fue incluida en una base de datos creada ex profeso en el software Filemaker Proß. Finalmente, y ya en el laboratorio, obtuvimos los calcos a través de las imágenes digitales y mediante el uso de distintos software de diseño gráfico (Angás y Bea, 2015).

A continuación, se resume el catálogo de grafías paleolíticas de la cueva de El Morrón (Tabla III):

Grupo I. El primer conjunto gráfico se localiza al fondo del sector este de la Sala Principal, en el techo, a una altura de 62 centímetros y sobre un soporte de roca encajante, ligeramente convexo y agrietado. Desde este lugar, se observa el Conducto de Acceso y levemente la luz exterior, si bien, la iluminación solar no alcanza la zona.

Las dimensiones del grupo son 60 centímetro de alto y 40 de ancho. El espacio subterráneo donde se encuentra es reducido, es decir, el tránsito humano por esta área resulta complejo pero sin contacto obligado con el techo. El estado de conservación es malo, ya que los pigmentos están notablemente desvaídos y preservan escasa carga de colorante. Este grupo ya fue descrito grosso modo por uno de nosotros (J.L.S.T.) en 1982. 


\begin{tabular}{|c|c|c|c|c|}
\hline Sector & Grupo & Grafía & Tema & Técnica \\
\hline \multirow{4}{*}{ Sala Principal } & \multirow{4}{*}{ I } & 1 & Mancha & Pintura roja \\
\hline & & 2 & Mancha & Pintura roja \\
\hline & & 3 & Mancha & Pintura roja \\
\hline & & 4 & Línea & Pintura negra \\
\hline \multirow{9}{*}{ Camarín de las Pinturas } & 11 & 1 & Figurativo-cáprido & Pintura negra \\
\hline & \multirow{2}{*}{ III } & 1 & Figurativo-cáprido & Pintura roja \\
\hline & & 2 & Manchas & Pintura roja \\
\hline & IV & 1 & Línea & Pintura negra \\
\hline & \multirow{5}{*}{ v } & 1 & Trazos(5)-posible zoomorfo & Pintura roja \\
\hline & & 2 & Mancha & Pintura roja \\
\hline & & 3 & Mancha & Pintura roja \\
\hline & & 4 & Mancha & Pintura roja \\
\hline & & 5 & Línea & Pintura negra \\
\hline
\end{tabular}

Tabla 3: Manifestaciones gráficas paleolíticas de la cueva de El Morrón / Paleolithic art, El Morrón cave.

I.1. Mancha informe de tonalidad roja, con forma tendente a longitudinal, con unas dimensiones de 1,5 centímetros de longitud y 0,3 de anchura; el modo de ejecución es el arrastre y el medio de ejecución es difícil determinarlo con exactitud, aunque consideramos que se trata de alguna zona somática (Fig. 4C).
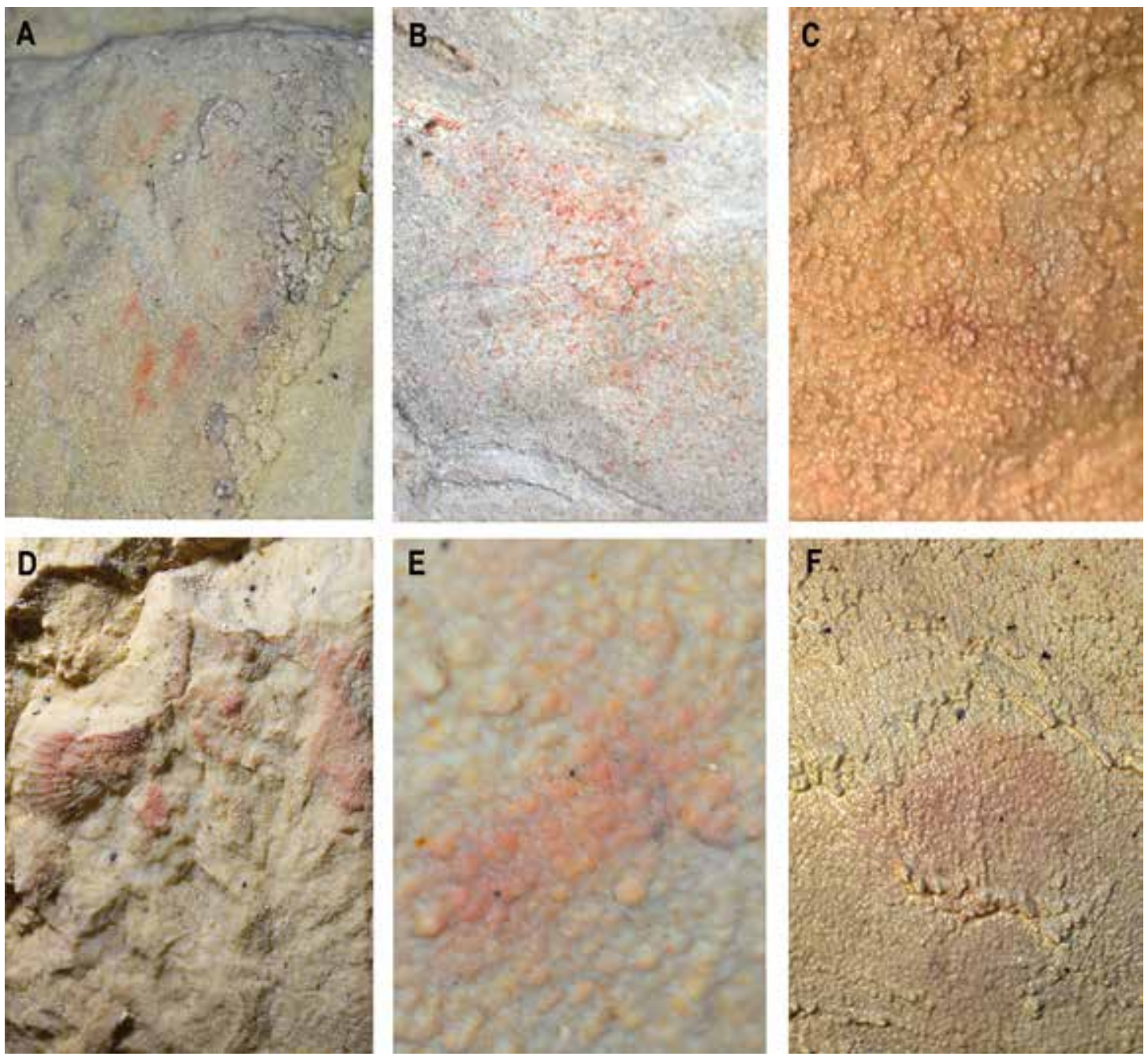

Fig. 4. Conjunto de manchas rojas de la cueva de El Morrón / Group of red stains, El Morrón cave. 
I.2. Mancha informe de tonalidad roja, con forma tendente a longitudinal, con unas dimensiones de 15 centímetros de longitud y 2,5 de anchura; el modo de ejecución es el arrastre y el medio de ejecución tampoco ha sido posible caracterizarlo.

I.3. Mancha informe de tonalidad roja, con forma tendente a circular, con unas dimensiones de 3 centímetros de longitud y 2,5 de anchura; el modo de ejecución es la impresión y el medio de ejecución tampoco ha sido posible caracterizarlo (Fig. 4B).

I.4. Trazo en tonalidad negra, con forma longitudinal algo arqueado; el modo de ejecución es el arrastre y el medio de ejecución impreciso. Sus dimensiones son 13 centímetros de longitud por 1,5 de anchura media (Fig. 8B). El modo de impregnación del pigmento en el soporte, la pátina que presenta, la técnica y su vinculación con las demás evidencias rojas del grupo I, nos empujan a considerar este elemento de probablemente cronología prehistórica, aunque debemos hacer hincapié que la cavidad presenta numerosos tizonazos negros de evidente apariencia reciente.

Grupo 2. Este conjunto está formado únicamente por una figura de cáprido en tonalidad negra, ubicado en el techo del Camarín de las Pinturas, a una altura de 110 centímetros y sobre un soporte de roca encajante cóncavo-convexo y agrietado. A este sector no alcanza la luz solar ni se observa la boca de la cavidad; el tránsito humano por este espacio es dificultoso, debiendo permanecer de rodillas o agachado para no chocar con el techo. El motivo presenta "...cornamenta [doble] de único arco, la línea dorsal con grupa redondeada se interrumpe a la altura de los desaparecidos cuartos traseros (tan sólo quedan restos de lo que podrían ser el inicio de las extremidades posteriores), las patas delanteras están figuradas por un simple trazo vertical muy saturado de color; grueso cuello. Aspecto más macizo y pesado que el cáprido rojo. Perfil orientado hacia la izquierda" (Sanchidrián, 1982: 5-8). Su estado de conservación, hoy día, es malo, con numerosos puntos del trazo recubiertos por barro, sobre todo en la extremidad delantera (Fig. 5).

Grupo 3. Este grupo está compuesto por un cáprido en color rojo y una mancha roja a 32 centímetros en línea recta hacia la izquierda del motivo figurativo. El soporte es un lienzo vertical de roca encajante agrietado localizado en la pared noreste del Camarín de las Pinturas. Del mismo modo que en el grupo anterior, este conjunto está situado en oscuridad total y el tránsito por este punto es complejo.

III.1. El cáprido rojo se localiza a 85 centímetros del piso actual. Sus dimensiones son 24 centímetros de longitud y 16 de altura, presenta una "...cabeza imprecisa con gran cuerna ondulada hacia atrás en doble arco, barba indicada, línea dorsal sinuosa, cola al parecer señalada por mancha aislada en los cuartos traseros, extremidad posterior con esbozo de representación de las articulaciones, despiece ventral y extremidades delanteras formadas por dos trazos paralelos. Se presenta en actitud de "salto". Su posición con respecto al suelo es horizontal y está dibujada sobre plano vertical, en perspectiva lateral izquierda" (Sanchidrián, 1982: 5). Además, esta figura tiene una morfología notablemente cambiante en función del ángulo de observación. Su estado de conservación, hoy día, es muy malo, el pigmento se localiza corrido, lo cual ha provocado la imprecisión de los trazos y presenta numerosos puntos de barro (Fig.6). Por ello, para la realización del calco digital nos hemos servido de la diapositiva tomada en 1981 por uno de nosotros (J.L.S.) (Fig. 7).

III.2: Mancha de color rojo de tendencia subcircular de 3,5 centímetros de anchura y 2,7 centímetros de altura. Se ubica a 90 centímetros del piso en un soporte de roca encajante escamado. La mancha está formada por un conjunto de micro-manchas arrastradas hacia el lado derecho. El medio de ejecución es difícil de precisar, si bien podemos desechar la mano y los dedos, el lápiz y el pincel. De nuevo, apuntamos a un componente somático, en esta ocasión nos inclinamos más por el pelo o algún elemento que portaran en la cabeza, dada la situación y el modo de ejecución de la mancha. Su estado de conservación es bueno, aunque posee escasa carga de pigmento. Esta evidencia parietal es inédita (Fig. 4A).

Grupo 4. Trazo negro discontinuo y rectilíneo inclinado, localizado a 52 centímetros del suelo actual en la pared noreste del Camarín de las Pinturas, en la entrada de una grieta reducida que se abre al frente de la cabra roja, en un soporte inclinado, escamado e irregular. Tiene 8 centímetros de longitud y 0,5 de anchura media, se encuentra parcialmente recubierto por una capa de concreción por ello hemos considerado su posible adscripción prehistórica (sin olvidar que la cavidad conserva numerosos tizonazos de evidente apariencia reciente), el modo de ejecución es el arrastre, el medio de ejecución es un lápiz probablemente de carboncillo. Su estado de conservación es bueno. Este motivo fue detectado en el catálogo anterior (Fig. 8A).

Grupo 5. El último conjunto gráfico se localiza en la pared oeste de la grieta que se abre al frente de la cabra roja, formada por varios bloques desprendidos de roca encajante. El espacio es tremendamente reducido, sólo cabe una persona tendida casi tocando ambas paredes del recinto (Fig. 9B). Las dimensiones totales del lienzo son 120 centímetros de anchura y 72 de altura. Hemos tenido gran dificultad para obtener fotografías de los restos localizados en este punto, pues no había una distancia suficiente para una óptima documentación fotográfica. Para minimizar este problema, nos hemos ayudado del sofware Sofortbild(C) 1.3., el cual nos ha permitido disparar y controlar los parámetros de la cámara desde el ordenador portátil, ganando de este modo el espacio que ocupa el fotógrafo, y controlar desde fuera de este espacio, en modo Live View y en la pantalla del ordenador, todo aquello que estaba recogiendo el sensor de la cámara. Además, en general, 


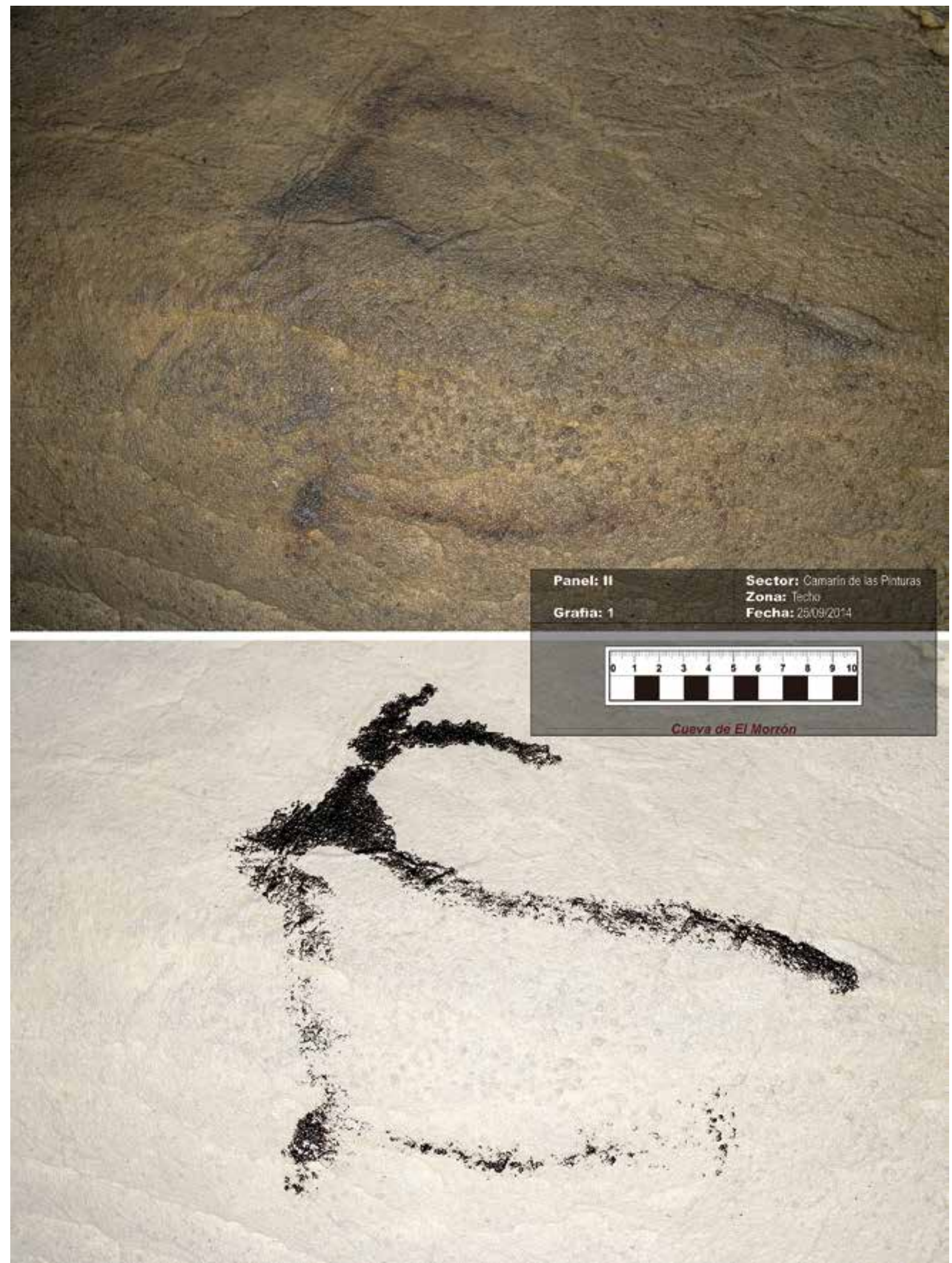

Fig. 5. Fotografía y calco de la cabra negra de la cueva de El Morrón / Photograph and tracing of the black ibex, El Morrón cave. 


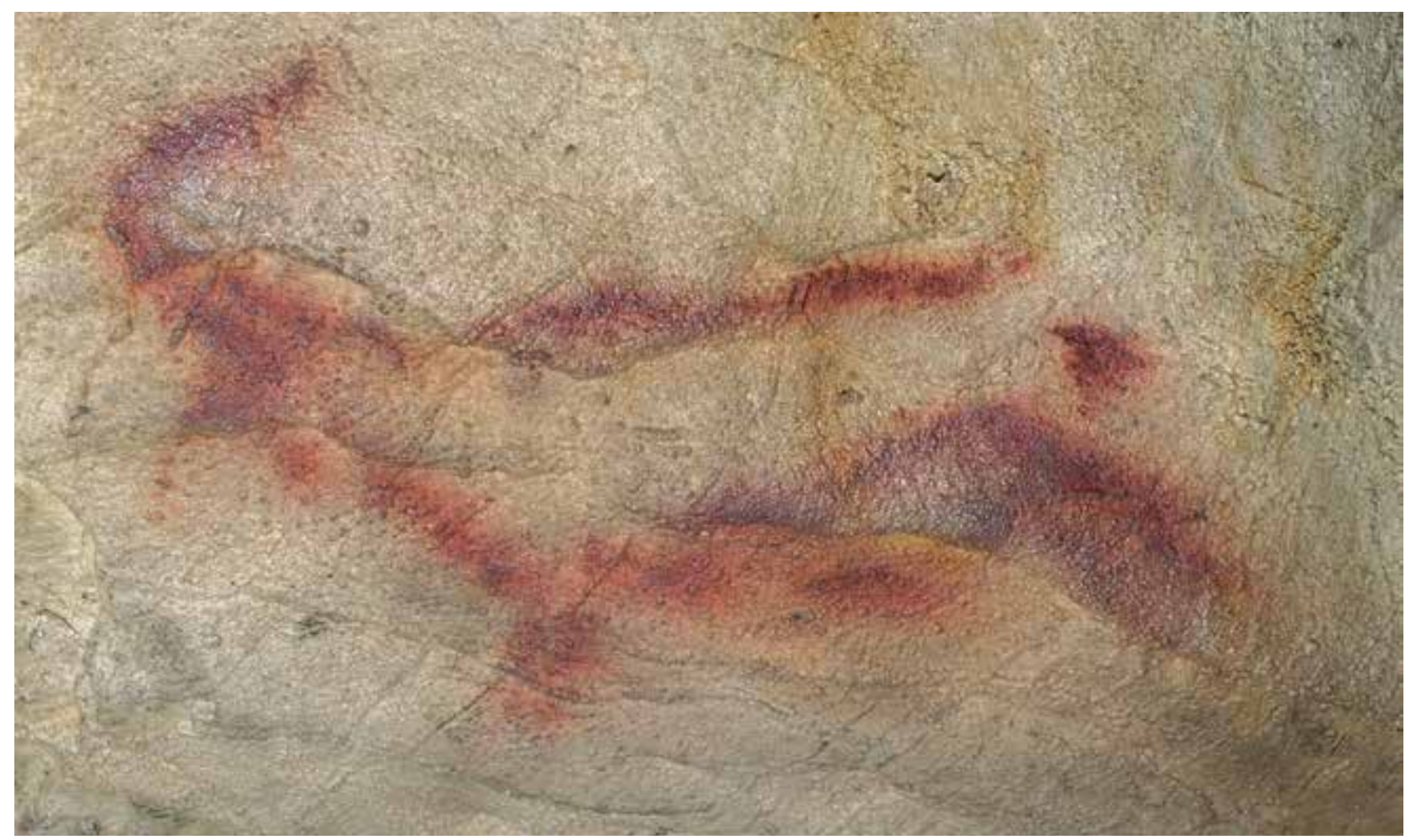

Fig. 6. Fotografía de la cabra roja de la cueva de El Morrón en la actualidad / Photograph of the red ibex at present, El Morrón cave.

todo el grupo posee un estado de conservación malo y los vestigios se encuentran muy perdidos con escasa carga de pigmentación. Este conjunto fue, en parte, registrado en el catálogo anterior.

V.1. Conjunto de 5 trazos curvos rojos ubicados a 60 centímetros de altura, abarcando una superficie de 70 por 40 centímetros. El modo de ejecución es el arrastre y el medio de ejecución parece un lápiz de ocre. Su estado de conservación es malo, apenas se observan, y su detección la realizamos apoyándonos en gran medida con el plugin DStrech(C. En el catálogo anterior se registraron sólo 3 de estos 5 trazos. El examen detallado de este conjunto nos invita a sugerir que se trata de los restos conservados de un posible motivo figurativo, en concreto, los trazos podrían corresponder con los cuartos traseros con un diseño similar de cáprido rojo, doble línea de vientre y arranque de las extremidades posteriores (Fig. 9, A2).

$\checkmark$.2. Mancha informe roja con tendencia longitudinal de 9 centímetros de altura, 2,5 centímetros de anchura, arrastrada mediante un medio de ejecución somático. Su soporte posee una particularidad añadida a lo descrito para el conjunto del grupo, ya que está ubicada sobre un amonites en un área escamada del mismo (Fig.4D).

V.3. Mancha polimorfa roja de 3 centímetros de altura y 2,5 de anchura, impresa mediante un medio de ejecución somático, localizada a 40 centímetros del piso (Fig.4E).
V.4. Mancha informe con tendencia longitudinal de 2 centímetros de altura y 1,5 de anchura, arrastrada de manera probablemente digital a 38 centímetros del suelo (Fig.4F).

V.5. Trazo corto negro de 1 centímetro de longitud y 0,5 de anchura, ubicado a 41 centímetros del piso. El medio y modo de ejecución son difíciles de precisar ya que se encuentra muy perdido y concrecionado (Fig. $8 \mathrm{C}$ ). Al igual que el elemento 1.4. el modo de impregnación del pigmento, la pátina, la técnica y su relación con las demás evidencias rojas del grupo nos empujan a considerar este elemento de probablemente cronología prehistórica.

En el catálogo anterior (Sanchidrián, 1982) se describen otros trazos negros y rojos dentro del Camarín de las Pinturas, los cuales en esta ocasión no hemos detectado. También, en este sector se localizaron restos de probable pintura amarilla. En este sentido, el examen bio-geológico de las superficies del cavernamiento indica que estas manchas son producto de la presencia de ácidos orgánicos en el agua de goteo.

Como hemos comentado, todas las pinturas paleolíticas documentadas se emplazan en los sectores más alejados de la boca de acceso a la cavidad. No obstante, desconocemos si bajo la espesa capa de negro de humo que recubre gran parte de los lienzos de la zona de entrada y Sala Principal se camuflan algunas grafías prehistóricas que han resultado imposibles de revelar. Por otra parte, el sector del Camarín de las Pinturas es 


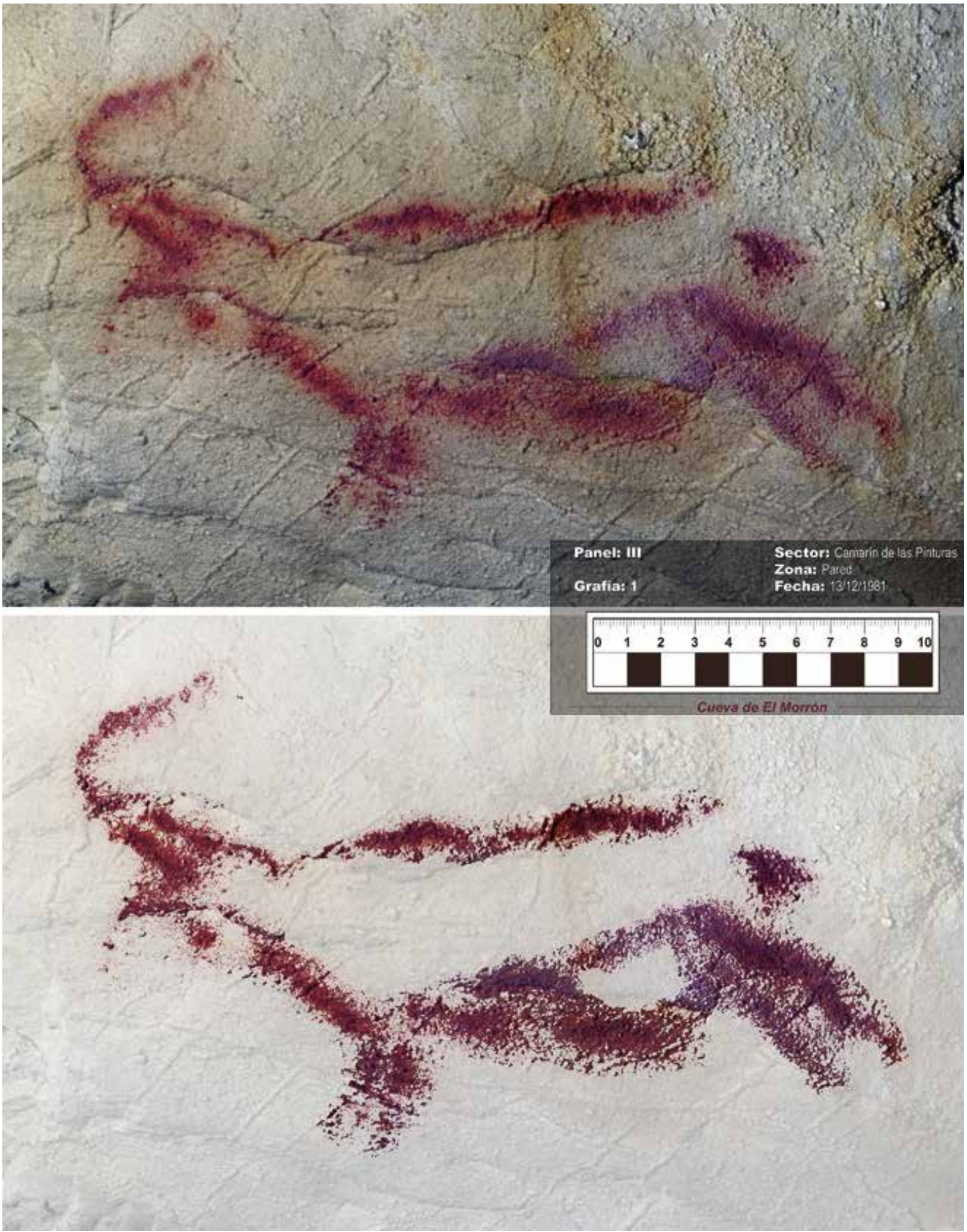

Fig. 7. Fotografía y calco de la cabra roja de la cueva de El Morrón / Photograph and tracing of the red ibex, El Morrón cave. 

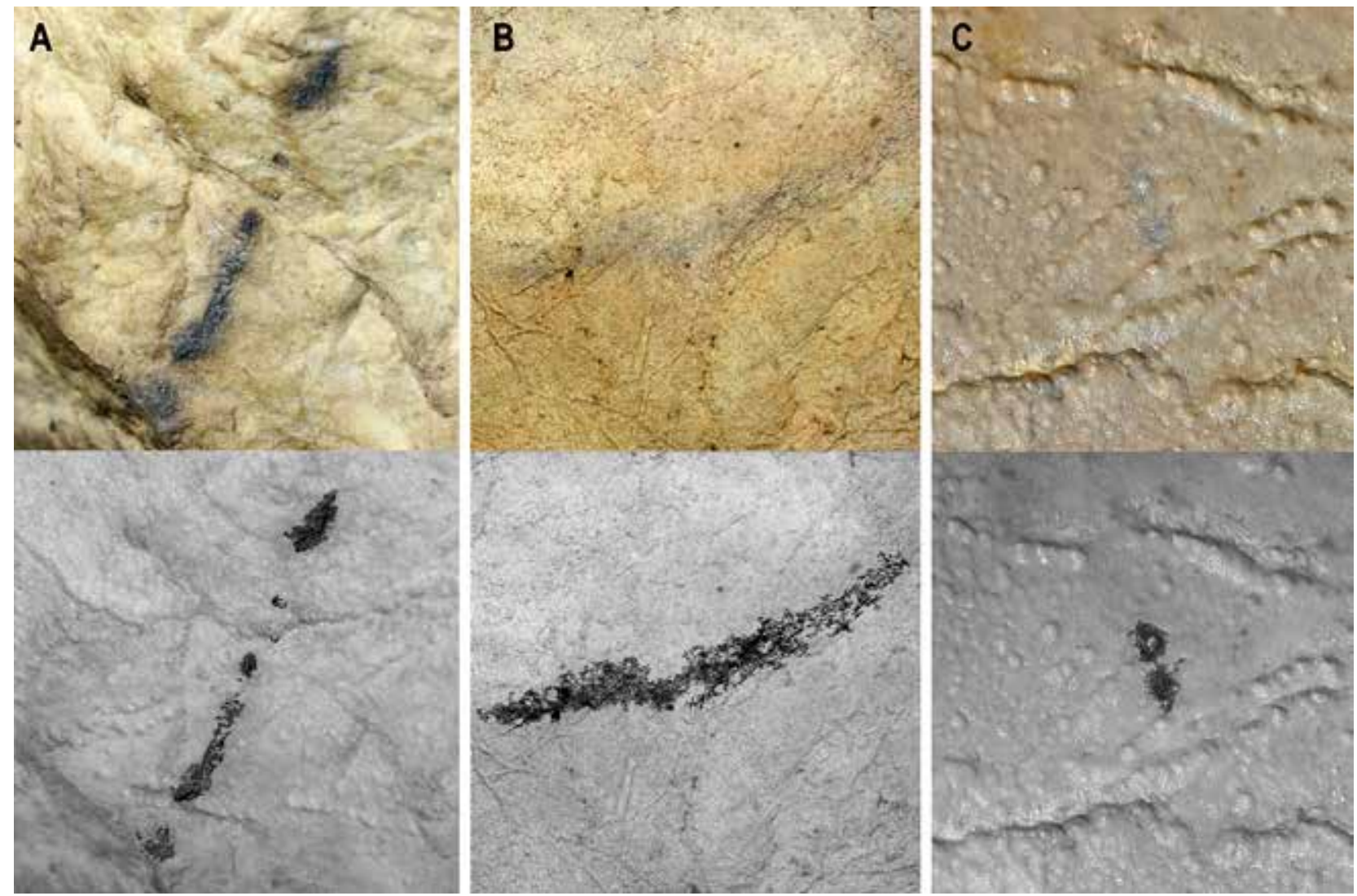

Fig. 8. Fotografías y calcos de los trazos negros de la Cueva de El Morrón / Photographs and tracings of black lines, El Morrón cave.
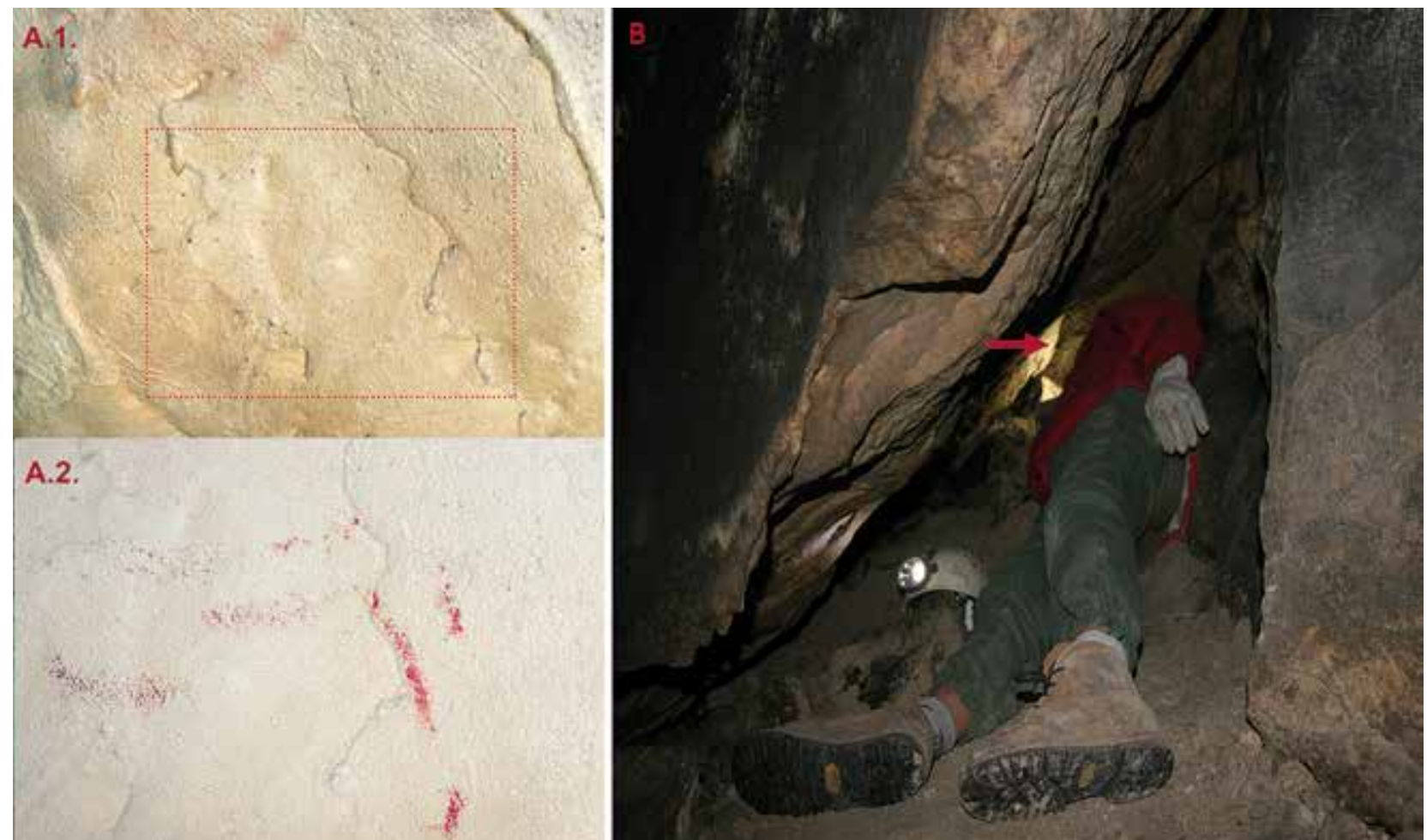

Fig. 9. Contexto espacial del grupo V y fotografías en detalle (A.1) y procesada con DStrech (A.2) de la grafía V.1. / Spatial context of group V, detailed (A.1) and DStretch-processed photographs (A.2) of sign V.1. 
un espacio estrecho de techo bajo, "oculto" al fondo del cavernamiento; la visualización completa del panel, a modo de diedro, que contiene las dos figuras de cabras (II.1 y III.1) (Fig. 10), solo es posible por una o dos personas tumbadas en el suelo boca arriba.

En la figura 11 presentamos los datos colorimétricos a partir de los puntos muestreados a través de dos fotografías digitales de sendos cápridos tomadas el 24/10/2014. El proceso de análisis colorimétrico seguido, a partir de la escala de color ColorCheker Passport, ha sido definido por J. Pereira (2013).

Además, en la prospección sistemática parietal, también se han registrado 53 conjuntos de grafitis contemporáneos a lo largo de toda la gruta, concen-

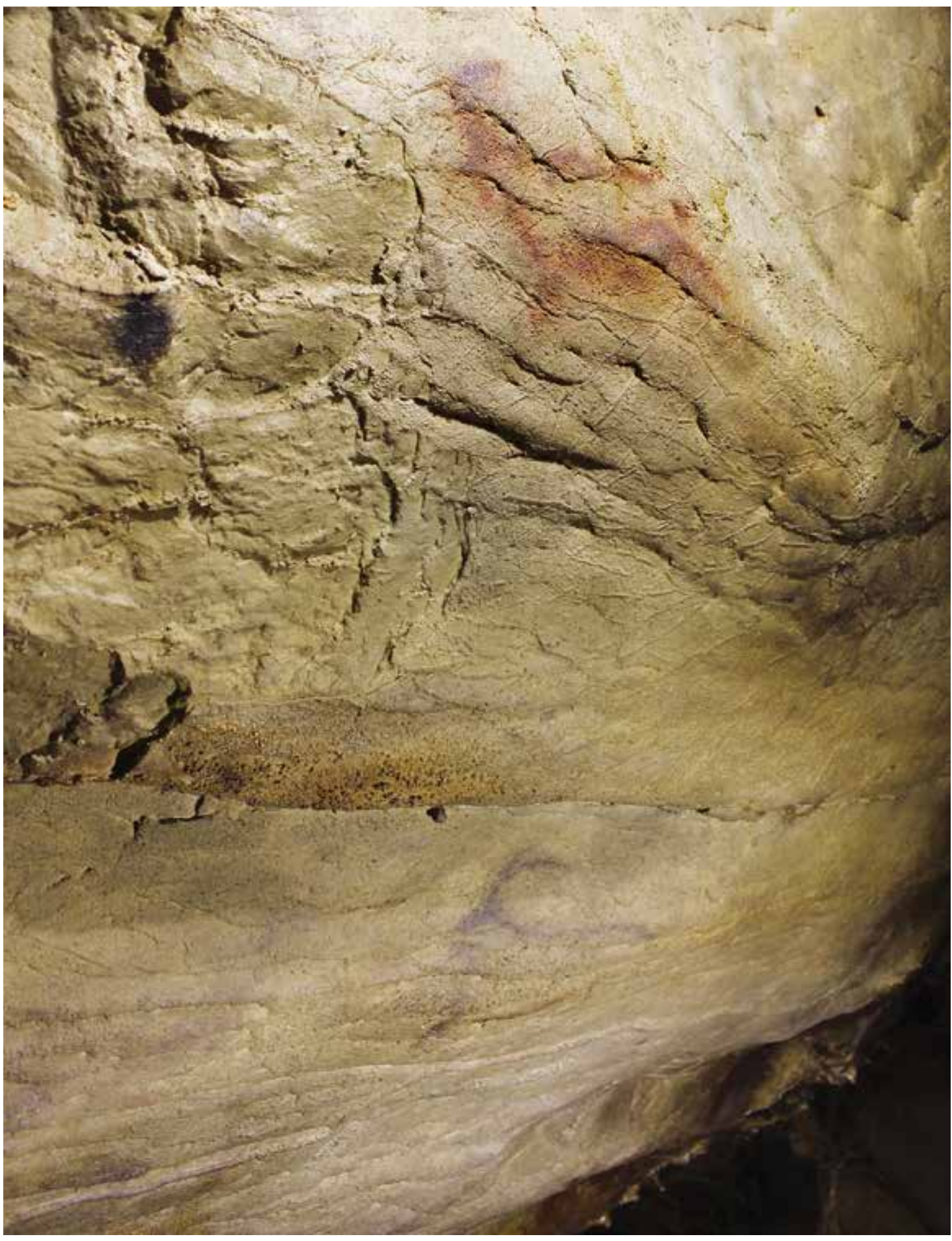

Fig. 10. Fotografia de las dos cacueva de El Morrón / Photographs of two ibexes of $\mathrm{El}$ Morrón cave. 


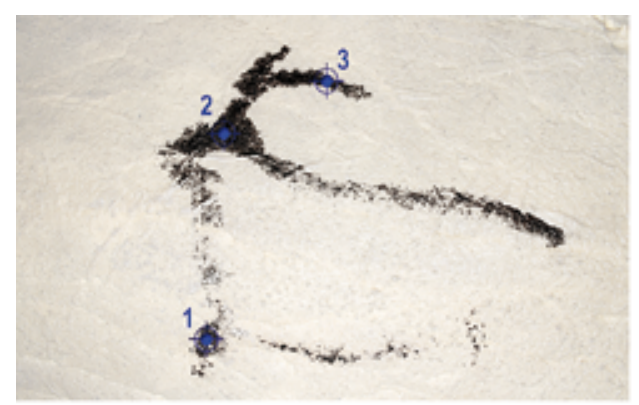

\begin{tabular}{|l|l|l|}
\hline Muestra \#1 & Muestra \#2 & Muestra \#3 \\
\hline L:20 & L:24 & L:26 \\
\hline a:2 & a:4 & a:4 \\
\hline b:5 & b:5 & b:9 \\
\hline Muestra H1 & Muestra +2 & Muestra \#3 \\
\hline R:37 & R:46 & R:50 \\
\hline G:35 & G:43 & G:46 \\
\hline B:31 & B:37 & B:38 \\
\hline
\end{tabular}

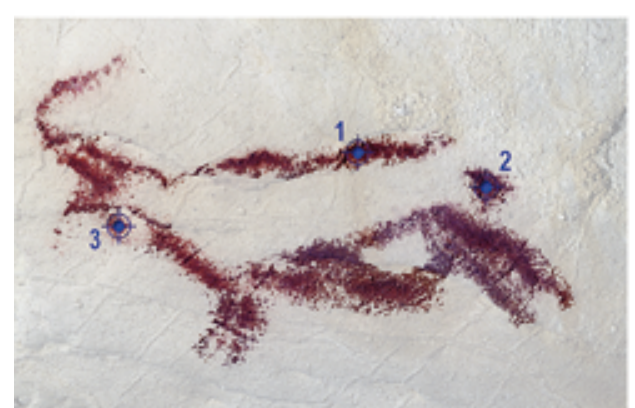

\begin{tabular}{|c|c|c|}
\hline Muestra \#1 & Muestra \#2 & Muestra \#3 \\
\hline L:55 & L:47 & L:64 \\
\hline $2: 24$ & $a: 21$ & $a: 19$ \\
\hline b. 26 & b: 20 & $b: 20$ \\
\hline Muestra \#1 & Muestra \#2 & Muestra \#3 \\
\hline R: 132 & R:108 & R: 153 \\
\hline Q:103 & G:84 & G.120 \\
\hline B:75 & B: 66 & B: 104 \\
\hline
\end{tabular}

Fig. 11. Datos colorimétricos RGB y LAB del estado actual de los cápridos de la cueva de El Morrón con indicación de las zonas de muestreo. / RGB and LAB colorimetric data for the current status of caprids at El Morrón cave, showing sampling areas.

trándose considerablemente en la pared noroeste de la Sala Principal y la zona más cercana a la entrada. Estas evidencias parietales están compuestas, comúnmente, por nombres y fechas de los visitantes modernos. Dichas incursiones datan en su mayoría desde 1981 a la actualidad, es decir, la publicación en prensa del hallazgo de las pinturas rupestres paleolíticas, sin la posterior salvaguarda del enclave, desencadenó la mayor oleada de actos vandálicos en la cavidad. Al mismo tiempo, hemos documentado un conjunto de grafitis fechados en época de la Guerra Civil Española, en concreto de 1938, al fondo de la Galería Lateral, junto con una moneda inserta en una grieta en este mismo espacio con acuñación de la década de los 50. Todo ello nos confirma que la cavidad era conocida y frecuentada por los vecinos del entorno con anterioridad al descubrimiento de las pinturas.

\subsubsection{Encuadre cronológico de las manifestaciones gráficas paleolíticas de la cueva de El Morrón}

El repertorio gráfico paleolítico de la cueva de El Morrón no resulta demasiado prolijo en elementos que permitan sustentar una amplia discusión sobre la cronología de las obras allí representadas. Por otro lado, los vestigios del contexto arqueológico interno detectados en nuestra última intervención tampoco ayudan en esta cuestión. Del mismo modo, los métodos de datación directa empleados en la actualidad para otorgar una fecha a las manifestaciones prehistóricas rupestres son, por el momento, inviables en la cavidad. Quizás, el motivo IV.1 al estar recubierto por una fina capa calcárea podría responder en el futuro a esas expectativas.
Así pues, centraremos nuestra atención en las dos figuras de cápridos. El ejemplar confeccionado en coloración negra (Fig. 5, motivo II.1) muestra unas proporciones corporales poco realistas o naturalistas, posee un cuerpo muy masivo y desequilibrado, con una cabeza pequeña respecto al cuerpo, y cuenta con escasos detalles anatómicos. Por su parte, el único elemento diagnóstico de la especie, la cornamenta, está ejecutada a tenor del esquema en $V$ lineal (Villaverde, 1994) en perspectiva "torcida", que en este caso sería más "Y" a través de dos arcos convergentes. La confección de la figura se centra en su mitad delantera desatendiendo los cuartos traseros, algo parecido a lo que podemos ver en la cabra de la plaqueta número 16116B extraída del nivel Solutrense inferior de Parpalló (Villaverde, 1994), que también está diseñada con una acusada descompensación entre la cabeza y el resto del cuerpo. En síntesis, reúne todos los elementos utilizados para describir las expresiones rupestres paleolíticas arcaicas o de edad pre-magdaleniense (Petrognani, 2013; Hernando, 2014; Villaverde, 2015), es decir, desproporción, desatención al contorno, perspectiva biangular-recta en la cornamenta, ausencia de elementos somáticos periféricos así como órganos sensoriales y detalles anatómicos internos.

Por otro lado tenemos el cáprido pintado con pigmento rojo (Fig. 6 y 7, motivo III.1). En este caso la figura está más completa y con una factura mucho más depurada, si bien en general sus caracteres formales aluden a ese "fondo común" del arte pre-magdaleniense. Aunque sus extremidades son muy escuetas, en el interior se trazó una línea de despiece ventral y fue plasmada en actitud de animación simétrica, todo 
lo cual encaja a la perfección con otro cáprido representado en la plaqueta número 16570 extraída de la capa Solutrense medio de Parpalló (Villaverde, 1994), en animación coordinada volante, modelado interior y parquedad en las extremidades; algo similar se puede igualmente rastrear en la plaqueta número 16112 correspondiente al Solutrense inferior-medio antiguo o incluso en la cabra de la plaqueta número 17019B del Solutrense medio (Villaverde, 1994) (Fig. 12).

El resto de las evidencias pictóricas detectadas durante la prospección (al margen de las líneas de tonalidad rojas que podrían corresponder con los cuartos traseros de un zoomorfo de construcción análoga a la cabra roja -Fig. 9, motivo V.1-), como serían los trazos en coloración negra, o los restos y manchas de tintas rojas, no obedecen a morfotipos estandarizados que pudieran orientar hacia una cronología precisa de su autoría. Al mismo tiempo, esos indicios de pintura tampoco pueden ser considerados como constitutivos del conjunto de signos normalizados y articulados que singularizan buena parte de la producción gráfica de cierto grupo de cavidades profundas de Andalucía, actualmente centrado en las provincias de Granada y sobre todo Málaga, como podrían ser los dispositivos gráficos antiguos de Nerja, el Horizonte E de La Pileta y las cuevas de Navarro, Victoria, Toro, Malalmuerzo (Sanchidrián, 1994; Medina-Alcaide y Sanchidrián, 2014; Villaverde, 2015).

El conjunto pictórico de la cueva de El Morrón se manifiesta bastante escueto y su contenido podría hacer plantear una especialización temática del mismo, en particular dedicado a los especímenes de cápridos, lo cual permitiría relacionar la cavidad giennense quizás con la temática regional más oriental del sur peninsular, por ejemplo con la zona de Murcia y su Cueva de las Cabras (Salmerón y Lomba, 1996). No obstante, desde nuestra óptica, no podemos categorizar al respecto sin tener presente que un porcentaje muy importante de los lienzos de la cavidad que tratamos, aparte de los múltiples grafitis modernos, se hallan cubiertos por una, a veces muy espesa, capa de negro de humo que tiñe prácticamente todas las superficies rocosas, impidiendo aseverar la no existencia de arte rupestre paleolítico debajo de ella.

De cualquier forma, después de varias decenas de años de su descubrimiento, la cueva de El Morrón continúa siendo un punto aislado en el mapa de dispersión de los sitios con expresiones rupestres pleistocenas del mediodía de la Península Ibérica. Sin embargo, en orden a su contextualización crono-cultural podría vincularse con el poblamiento paleo-superior del relativamente próximo yacimiento de Peña de la Grieta, en el municipio de Porcuna (Arteaga et al., 1998), donde se ha detectado una capa inferior con industrias de foliáceos adscrita al Solutrense medio y otra superior donde además surgen las puntas de pedúnculos y aletas, propias del Solutrense evolucionado.

\section{5.- CONCLUSIÓN}

El estudio arqueológico desarrollado en el marco de la Actividad Arqueológica Puntal de "Diagnóstico destinado a la preservación y propuesta de medidas correctoras para la conservación de la cueva de El Morón (Torres, Jaén)" ha permitido una revisión actualizada del estado de la gruta en este ámbito treinta y cinco años después de la última publicación de referencia. La prospección sistemática de las superficies pavimentarias ha puesto de manifiesto que la cavidad contiene en su interior restos arqueológicos adicionales al conjunto gráfico paleolítico. Por lo general, se trata de evidencias arqueológicas poco diagnósticas, entre los cuales sobresalen varios restos óseos humanos, uno de ellos datado por C14-AMS en época altomedieval, y localizados en el interior de al menos una estructura circular antrópica construida a base de bloques de mediano tamaño. En cuanto a la prospección parietal han sido registradas nuevas evidencias parietales paleolíticas que se suman al repertorio ya publicado, en concreto, los cuartos traseros de un posible zoomorfo, varias manchas rojas informes y trazos lineales negros;
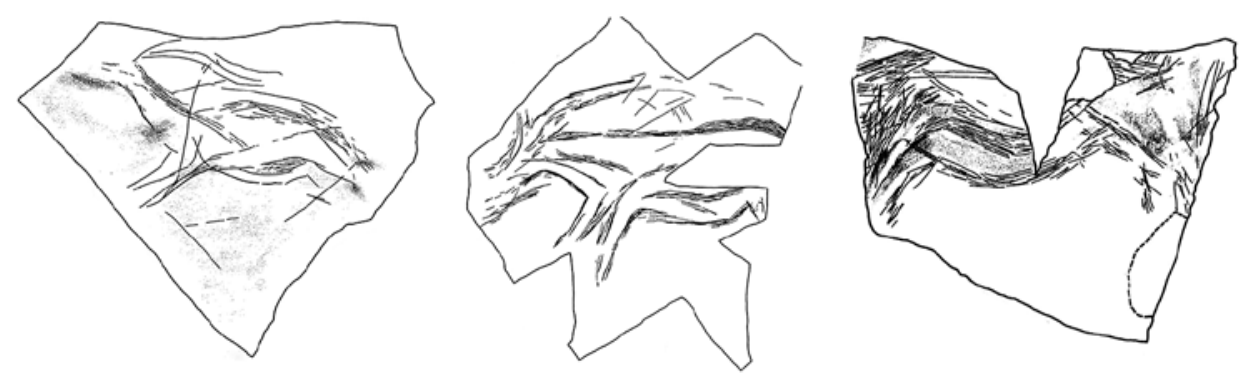

\begin{tabular}{|c|c|c|}
\hline $\mathrm{N}$ catálogo & 16.570 & $17.019(\mathrm{~B})$ \\
\hline Nivel-cronocultural & Solutrense medio & Solutrense medio \\
\hline
\end{tabular}

16.112

Villaverde, 1994

Fig. 12. Conjunto de plaquetas de la cueva de Parpalló paralelizadas con el cáprido rojo de El Morrón, con indicación del número de catálogo, el nivel cronocultural y la bibliografía / Set of plaquettes from the Parpalló cave, alongside the red caprid at El Morrón, showing catalogue number, chrono-cultural level and bibliography. 
asimismo, se ha constatado un importante deterioro de los motivos figurativos ya conocidos.

\section{AGRADECIMIENTO}

Al Ayuntamiento de Torres, y en especial a Roberto Moreno, por su disposición y facilidades que siempre nos ha brindado para el desarrollo de este trabajo, así como, al Instituto de Investigación Cueva de Nerja por su colaboración desinteresada en el estudio de esta cavidad con arte paleolítico de Andalucía. Además, damos las gracias a J.A. Hierro Gárate y a Cristina Camarero por sus comentarios, los cuales han enriquecido este estudio. Gracias, también, a todos/as los/as compañeros/as del Área de Prehistoria de la Universidad de Córdoba que participaron en las tareas de prospección. Por último, indicar que $\mathrm{M}^{\mathrm{a}}$ Ángeles Medina-Alcaide tiene un contrato de investigación predoctoral FPUMECD en la UPV/EHU, que forma parte del grupo de investigación en Prehistoria IT-622-13 y del proyecto HAR2014-53536-P.

\section{BIBLIOGRAFIA}

Angás, J., Bea, M., 2015. Propuesta conceptual y metodológica en la documentación gráfica y geométrica del arte rupestre: proyecto ARAM (arte rupestre y accesibilidad multimedia). In: Medina Alcaide, M.A. et al. (Eds.), Sobre rocas y huesos: las sociedades prehistóricas y sus manifestaciones plásticas, 344-361, Universidad de Córdoba y Fundación Cueva de Nerja, Córdoba.

Artega, O., Ramos, J., Roos, A.M., 1998. La Peña de la Grieta (Porcuna, Jaén). Una nueva visión de los cazadores-recolectores del Mediodía Atlántico-Mediterráneo desde la perspectiva de sus modos de vida y de trabajo en la cuenca del Guadalquivir. In: Sanchidrián Torti, J.L., Simón Vallejo, M.D. (Coords.), Las Culturas del Pleistoceno Superior en Andalucía, 75-109, Málaga.

Bonilla, J.A., Blanco, R., Ruiz, R., 1982. Campaña espeleológica "Aznatín 81". Mesataria: Revista de la Federación Castellana-norte de Espeleología 0, 73-100.

Díaz-Zorita, M., García-Sanjuán, L., 2012. Las inhumaciones medievales del atrio del dolmen de Menga (Antequera, Málaga): estudio antropológico y cronología absoluta. Menga: Revista de Prehistoria de Andalucía 3, 237-249.

Gutiérrez, S., 1986. Cerámicas comunes altomedievales: contribución al estudio del tránsito de la antigüedad al mundo paleoislámico en las comarcas meridionales del País Valenciano. Lucentum V, 147-167.

Gutiérrez, E., Hierro, J.A., 2012a. Nuevas evidencias sobre el uso de las cuevas de Cantabria durante la Tardoantigüedad y la Alta Edad Media. Primeros resultados del Proyecto Mauranus. Sautuola XVI-XVII, 263-280.

Gutiérrez, E., Hierro, J.A., 2012b. El uso de las cuevas naturales en Cantabria durante la Antigüedad tardía y los inicios de la Edad Media (siglos V-X). Kobie Paleoantropología 31, 175-206.

Hernando, C., 2014. La sociedad a través del arte: las tradiciones gráficas premagdalenienses en la región cantábrica. Tesis Doctoral. Universidad de Salamanca, Salamanca.

Hierro, J.A., 2002. Arqueología de la Tardoantigüedad en Cantabria: yacimientos y hallazgos en cueva. Nivel Cero 10, 113-128.
Hierro, C., 2011. La utilización sepulcral de las cuevas en época visigoda: los casos de Las Penas, La Garma y el Portillo del Arenal (Cantabria). Munibe Antropologia-Arkeologia 62, 351-402.

IGME, 1992. Mapa Geológico de España, escala 1:50.000. Torres (hoja 948).

López, M.G., Soria, M., Álvarez, J.A., Garcia, F., Gila, M., Valverde, F., 1982. Las pinturas rupestres paleolíticas de la Cueva El Morrón, Jimena, Jaén. La Carolina.

López, M.G., Soria, M., 1985. Las pinturas rupestres paleolíticas de la Cueva El Morrón, Torres, Jaén. Ars Praehistorica. Anuario Internacional de Arte Prehistórico 2, 195-206.

Medina-Alcaide, M., Sanchidrián, J.L., 2014. Los signos integrados de Pileta-E: análisis a diferentes profundidades de campo. In: Medina-Alcaide M.A. et al (Eds.), Sobre rocas y huesos: las sociedades prehistóricas y sus manifestaciones plásticas, 116-129, Universidad de Córdoba y Fundación Cueva de Nerja, Córdoba.

Pereira, J., 2013. Gestión del color en proyectos en digitalización. Marcombo Ediciones Técnicas, Barcelona.

Petrognani, S., 2013. De Chauvet à Lascaux. L art des cavernes, reflet de sociétés préhistoriques en mutation, Paris.

Reimer, P. J., Bard, E., Bayliss, A., Beck, W., Blackwell, P., Bronik, C., Buck, C., Cheng, H., Edwards, L., Friedrich, M., Grootes, P., Guilderson, T., Haflidason, H., Hajdas, I., Hatté, Ch., Heaton, T., Hoffmann, D., Hogg, A., Hughen, K., Kaiser, F., Kromer, B., Manning, S., Niu, M., Reimer, R., Richards, D., Scott, M., Southon, J., Staff, R., Turney, Ch., Van Der Plicht, J.J., 2013. IntCal13 and Marine13 radiocarbon age calibration curves 0-50,000 years cal BP. Radiocarbon 55(4), 1869-1887.

Ruiz, J.F., Pereira, J., 2014. The colours of rock art. Analysis of colour recording and communication systems in rock art research. Journal of Archaeological Science 50, 338-349.

Salmerón, J., Lomba, J., 1996. El Arte Rupestre Paleolítico. Historia de Cieza 1, 71-89. Murcia.

Sanchidrian, J.L., 1982. La Cueva del Morrón (Jimena, Jaén). Zephyrus XXXIVXXXV, 4-11.

Sanchidrian, J.L., 1994. Arte rupestre de la Cueva de Nerja. Patronato de la Cueva de Nerja, Málaga.

Sanchidrián, J.L., Medina-Alcaide, M.A., Romero, A.J., Del Roral, Y., Liñán, C., Cobos, J.M., Jiménez-Mena, J., Molina-Crespo, C., Peña, J.A, Ruiz-Márquez, R., Torres, A., Valverde, R., 2015. Interdisciplinary review of current environmental conservation of Cueva de El Morrón (Torres, Jaén)/ Revisión interdisciplinar del estado actual de conservación de la Cueva de El Morrón. IFRAO2015/ARKEOS 37, 483-488.

Sanz de Galdeano, C., García-Tortoa, F.J., Peláez, J.A., 2013. Estructura del Prebético de Jaén (sector de Bedmar). Su relación con el avance del Subbético y con fallas en el basamento. Revista de la Sociedad Geológica de España 26(1), 55-68.

Solaun, J.L., 2006. La cerámica medieval en el País Vasco (siglos VIII-XIII). Gobierno Vasco, Servicio de Publicaciones / Universidad del País Vasco, Servicio de Publicaciones, Vitoria / Leioa.

Villaverde, V., 1994. Arte Paleolítico de la Cova del Parpalló. Servei d'Investigació Prehistòrica, Diputació de València, Valencia.

Villaverde, V., 2015. Palaeolithic art in the Iberian Mediterranean region. Characteristics and territorial variation. In: Bueno, P., Bahn, P.G., Prehistoric Art as Prehistoric Culture. Studies in Honour of Professor Rodrigo de Balbín-Behrmann, Archaeopress Publishing LTD. Oxford. 